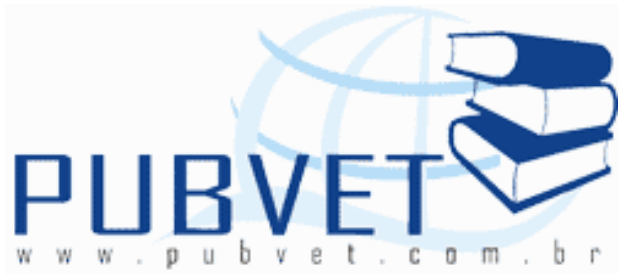

PUBVET, Publicações em Medicina Veterinária e Zootecnia.

\title{
Contaminação microbiológica em mel de abelhas (Apis mellifera) não inspecionado comercializado no Mercado da Produção em Maceió
}

Rejane Silva de Lima ${ }^{1}$, Yamina Coentro Montaldo ${ }^{1}$, Ana Karina de Aguiar

Calheiros ${ }^{1}$, Tania Marta Carvalho dos Santos ${ }^{1}$, Diogo de Barros Mota Mélo ${ }^{2}$

${ }^{1}$ Universidade Federal de Alagoas, Departamento de Zootecnia, Rio Largo AL.

2 Instituto Federal de Alagoas, Departamento de Produção Pesquisa e Inovação, Satuba - AL.

\section{Resumo}

Embora o mel seja um produto que por suas características físicas e químicas apresente elevado grau de resistência diante da proliferação de microrganismos, a ação de fatores externos pode vir a influenciar negativamente sua qualidade final. $O$ presente trabalho teve como objetivo avaliar o nível de contaminação microbiológica em amostras de méis não inspecionados no Mercado da Produção em Maceió. Os experimentos foram conduzidos no laboratório de Microbiologia Agrícola do Centro de Ciências Agrárias da Universidade Federal de Alagoas. Foram coletadas dez amostras de mel em diferentes pontos, sendo cinco com rótulo e cinco sem rótulo. As amostras foram submetidas a contagem de microrganismos mesófilos, determinação do número mais provável (NMP) de coliformes totais e termotolerantes. Das amostras analisadas, somente $20 \%$ apresentaram boas 
LIMA, R.S. et al. Contaminação microbiológica em mel de abelhas (Apis mellifera) não inspecionado comercializado no Mercado da Produção em Maceió. PUBVET, Londrina, V. 5, N. 6, Ed. 153, Art. 1028, 2011.

condições higiênico-sanitárias. A contagem de bactérias mesófilas revelou-se insatisfatória em 9 amostras das 10 analisadas. A presença de sujidades ocorreu em todas as amostras.

Palavras-chaves: Mel, Coliformes, Sujidades, Abelhas, Apis mellifera

\title{
Microbiological contamination in honey bee (Apis mellifera) not inspected the marketing of marketed production of Maceió
}

\begin{abstract}
Although honey is a product that by its physical and chemical characteristics present high degree of resistance to the organisms, the action of external factors might negatively influence their final quality. This study aimed to evaluate the level of microbiological contamination in samples of honey uninspected Marketing Production in Maceio. The experiments were conducted in the laboratory of Agricultural Microbiology of the Center for Agrarian Sciences, Federal University of Alagoas. Ten samples were collected at different points of honey, five-labeled and five unlabeled. The samples were subjected to mesophilic count, determining the most probable number (MPN) of total and fecal coliforms. Of the samples analyzed, only $20 \%$ had good sanitary conditions. The count of mesophilic bacteria proved to be unsatisfactory in nine of 10 samples analyzed. The presence of impurities occurred in al sample.
\end{abstract}

Keywords: Honey, Coliforms, Dirt, Bees, Apis mellifera

\section{INTRODUÇÃO}

A ação de fatores externos (ambiente, condição de manipulação e estocagem) pode vir a influenciar negativamente sua qualidade final; o mel pode ser um veículo de muitos microrganismos potencialmente patogênicos, além da existência de leveduras osmofílicas. Assim a higiene do pessoal e 
LIMA, R.S. et al. Contaminação microbiológica em mel de abelhas (Apis mellifera) não inspecionado comercializado no Mercado da Produção em Maceió. PUBVET, Londrina, V. 5, N. 6, Ed. 153, Art. 1028, 2011.

equipamentos é de suma importância na manutenção da qualidade do mel (RUIZ, 1992).

As características microbiológicas do mel estão relacionadas à qualidade e a segurança deste alimento. Os microrganismos de importância são primariamente leveduras, fungos filamentosos e bactérias formadoras de esporos. Estes microrganismos podem estar envolvidos em atividades de deterioração do produto, produção de enzimas, toxinas, conversão metabólica do alimento, produção de fatores do crescimento (vitaminas e aminoácidos) e fatores de inibição de microrganismos competidores (GOMES, 2006)

Fontes primárias de contaminação microbiana no mel (antes da colheita) são muito difíceis de controlar, como por exemplo: o pólen, o aparelho digestivo das abelhas melíferas, pó, ar, solo e néctar. As fontes secundárias (depois da colheita) que influenciam qualquer produto alimentício também são fontes de contaminação para o mel. Estas incluem os manipuladores, contaminação cruzada, equipamentos e instalações.

O presente trabalho teve como objetivo avaliar o nível de contaminação microbiológica em amostras de méis não inspecionados comercializados no Mercado da Produção em Maceió - AL.

\section{REVISÃO DE LITERATURA}

A apicultura é uma das atividades capazes de causar impactos positivos, tanto sociais quanto econômicos, além de contribuir para a manutenção e preservação dos ecossistemas existentes (CAMARGO et al., 2002). Pelo potencial de geração de trabalho e renda que possui, seu desenvolvimento de forma sustentada pode constituir importante mecanismo de promoção econômico-social de amplos segmentos da população rural, que formam a maior parcela entre os trabalhadores dessa atividade (PARREIRAS, 2007).

O mel é um produto alimentício produzido pelas abelhas melíferas, a partir do néctar das flores ou das secreções procedentes de partes vivas das 
LIMA, R.S. et al. Contaminação microbiológica em mel de abelhas (Apis mellifera) não inspecionado comercializado no Mercado da Produção em Maceió. PUBVET, Londrina, V. 5, N. 6, Ed. 153, Art. 1028, 2011.

plantas ou de excreções de insetos sugadores de plantas que ficam sobre partes vivas de plantas, que as abelhas recolhem, transformam, combinam com substâncias específicas próprias, armazenam e deixam maturar nos favos da colméia. É uma solução concentrada de açúcares com predominância de glicose e frutose (MAPA, 2001). Contém ainda uma mistura complexa de outros hidratos de carbono, enzimas, aminoácidos, ácidos orgânicos, minerais, substâncias aromáticas, pigmentos e grãos de pólen podendo conter cera de abelhas procedente do processo de extração. É considerado um alimento de alto valor energético para o organismo humano (CRANE, 1987) uma vez que, 1 grama de mel contém 6,4 kcal (ETTINGER, 2002).

As fontes primárias de contaminação microbiana do mel como o pólen, o trato digestório de abelhas melíferas, a poeira, o ar, a terra e o néctar são considerados de difícil controle, quando comparadas com as fontes secundárias que podem ser controladas através da implantação de boas práticas de fabricação no entreposto. As fontes secundárias incluem: a exposição ao ar durante a extração do mel; os manipuladores (infecções de pele, espirros ou contaminação fecal); as contaminações cruzadas (animais ou produtos animais) e os equipamentos (incluindo resíduos de alimento e água). Além destas, pisos, paredes e tetos, também podem ser reservatórios de microrganismos e contaminar o alimento. Um alto índice de unidades formadoras de colônias de microrganismos vegetativos (os quais não são esperados e não podem se desenvolver no mel) por grama pode indicar uma contaminação recente (SNOWDON; CLIVER, 1996).

Segundo Sonwdon e Cliver (1996), relatos e pesquisas sobre contaminação de vírus e parasitas em mel, até o momento, são inexistentes em publicações científicas. Entretanto, bactérias e fungos encontrados nos ambientes da cadeia produtora do mel (favos, pólen, flores, solo e outros) estão comumente presentes no produto final. Dentre estes se encontram Actinetobacter spp, Bacillus spp, Clostridium spp, Corynebacterium spp, 
LIMA, R.S. et al. Contaminação microbiológica em mel de abelhas (Apis mellifera) não inspecionado comercializado no Mercado da Produção em Maceió. PUBVET, Londrina, V. 5, N. 6, Ed. 153, Art. 1028, 2011.

Pseudomonas spp, Psychrobacter spp e Vagococcus spp, provenientes do solo; espécies de Bacillus spp, Clostridium spp e Micrococcus spp do ar e poeira.

Leveduras do gênero Saccharomyces spp e Torula spp e outros microrganismos existentes em vegetais como Brochothrix spp, Citrobacter spp, Enterobacter spp, Erwinia spp, Flavobacterium spp, Lactobacillus spp, Luctococcus spp, Listeria spp e Pediococcus spp também podem ser isolados a partir do mel (SNOWDON; CLIVER, 1996).

A contaminação fúngica é importante, considerando a grande capacidade de dispersão destes microrganismos. A simples presença de estruturas fúngicas em substratos adequados pode implicar não somente em seu desenvolvimento, mas como na possível produção de micotoxinas concomitantemente (SNOWDON; CLIVER, 1996).

Em relação aos fungos filamentosos, alguns estão associados ao conteúdo intestinal das abelhas, à colméia e ao ambiente de forrageamento. Aspergillus spp foi isolados de intestinos de larvas de abelhas (HASIG; KAMBUROY, 1966), assim como os gêneros: Atichia spp, Coniothecium spp, Hormiscium spp, e Triposporium spp (HASIG; KAMBUROY, 1966

As bactérias formadoras de esporos são de importância na qualidade do mel (SNOWDON; CLIVER, 1996). Uma vez que estas possuem potencial genético para formarem esporos que sobrevivem no alimento podendo permanecer dormentes durante períodos de tempo extremamente longos, resistindo aos tratamentos térmicos. Os esporos bacterianos são resistentes a agentes como, calor, dessecamento, radiação, ácidos e desinfetantes químicos (MADIGAN et al., 2004).

Segundo Snowdon e Cliver (1996), as contagens bacterianas determinados no mel, variam de 1 a 5000 UFC/g. Esta variação pode estar associada ao tipo de amostra (artesanal ou industrializada), o tempo de estocagem do mel, época de colheita e a técnica de beneficiamento utilizada. 
LIMA, R.S. et al. Contaminação microbiológica em mel de abelhas (Apis mellifera) não inspecionado comercializado no Mercado da Produção em Maceió. PUBVET, Londrina, V. 5, N. 6, Ed. 153, Art. 1028, 2011.

Com exceção da pesquisa de Clostridium botulinum, há poucos relatos na literatura a respeito de bactérias no mel.

Desde o século passado, diversos trabalhos reportam a presença de esporos de Clostridium botulinum em mel de várias partes do mundo (MONETO et al. 1999).

Os insetos e os ácaros, além de depositarem suas dejeções sobre os alimentos causando doenças por fungos, bactérias, vírus, protozoários e helmintos, também podem contaminar os produtos com microrganismos que se encontram aderidos ao seu corpo e às suas pernas. Além disso, os ácaros podem desencadear processos alérgicos em indivíduos susceptíveis, quando ingeridos com alimentos (CORREIA \& RONCADA, 2002).

\section{MATERIAIS E MÉTODOS}

\subsection{LOCAL DE INVESTIGAÇÃO}

O experimento foi conduzido no Laboratório de Microbiologia Agrícola, do Centro de Ciências Agrárias, da Universidade Federal de Alagoas. Foram utilizadas dez amostras de mel não inspecionadas, sendo cinco com rótulo e cinco sem rótulo, em diferentes pontos do mercado da produção em Maceió.

\subsection{PREPARO DAS AMOSTRAS}

Os procedimentos utilizados no preparo das amostras seguiram as recomendações descritas no Compendium of the Microbiological Examination of Foods (VANDERZANT; SPLITTSTOESSER, 1992). De cada amostra de mel, uma sub-amostra de 25 gramas foi suspensa em $225 \mathrm{ml}$ da solução Água Peptonada $0,1 \%$ obtendo-se a concentração de $10^{1}$, a partir dessa diluição foram transferidos $10 \mathrm{ml}$ para $90 \mathrm{ml}$ formando a diluição $10^{2}$ e posteriormente a diluição $10^{3}$. Todos os materiais, como pipetas e meios de cultura, foram 
LIMA, R.S. et al. Contaminação microbiológica em mel de abelhas (Apis mellifera) não inspecionado comercializado no Mercado da Produção em Maceió. PUBVET, Londrina, V. 5, N. 6, Ed. 153, Art. 1028, 2011.

previamente esterilizados em autoclave a $121^{\circ} \mathrm{C}$ por $20 \mathrm{~min}$, com exceção das vidrarias que foram esterilizadas em estufa a $160^{\circ}$ por 2 horas.

\subsection{CONTAGEM DE FUNGOS}

Após agitação foram feitas diluições em série até $10^{3}$. Das diluições $10^{1}-$ $10^{3}$ alíquotas de $1,0 \mathrm{ml}$ foram depositadas em placas de Petri (três placas para cada diluição). Foi adicionada a cada placa $15 \mathrm{ml}$ do meio de cultura fundente e (44 \pm 1 ) homogeneizado com movimentos suaves em torno de oito ou 10 vezes. As Unidades Formadoras de Colônias foram calculadas através da seguinte fórmula:

$$
\mathbf{U F C} \mathbf{g}=\frac{X \cdot F D}{V}
$$

Onde: $\mathbf{X}=$ Média de cada diluição, $\mathbf{F D}=$ Fator de diluição e $\mathbf{V}=$ Volume da diluição adicionado à placa de Petri.

\subsection{CONTAGEM TOTAL DE MICRORGANISMOS AERÓBIOS MESÓFILOS}

Para esta avaliação, foram plaqueados em profundidade $1 \mathrm{ml}$ de cada diluição $10^{-1}$ até $10^{-3}$ em triplicata, utilizou-se o meio de cultivo PCA. Após o plaqueamento, as placas foram incubadas por $48 \mathrm{~h}$ a $32^{\circ} \mathrm{C}$. As placas com contagens entre 30 e 300 UFC foram selecionadas, onde foi feita a contagem das colônias.

\subsection{DETERMINAÇÃO DO NMP DE COLIFORMES}

Para a determinação do NMP (Número Mais Provável) de coliformes, foi utilizada a técnica dos tubos múltiplos, conforme metodologia descrita pela Associação Brasileira de Normas Técnicas (ABNT, 1991).

Essa técnica compreende duas fases distintas: o teste presuntivo, no 
LIMA, R.S. et al. Contaminação microbiológica em mel de abelhas (Apis mellifera) não inspecionado comercializado no Mercado da Produção em Maceió. PUBVET, Londrina, V. 5, N. 6, Ed. 153, Art. 1028, 2011.

qual recuperam as células e se detecta a presença de microrganismos fermentadores da lactose, e o teste confirmativo, onde se determina a população real de coliformes totais e termotolerantes.

No teste presuntivo foram utilizadas três séries de três tubos contendo Água Peptonada e tubos de Duram. No teste confirmativo, de cada amostra positiva, foi recolhido o tubo de maior diluição e realizadas semeaduras em tubos de ensaio contendo lactose-bile-verde brilhante $2 \%$ e tubos de Duram. As culturas foram incubadas a $44^{\circ} \mathrm{C}$ por 24 horas. Após a incubação, a presença de bactérias do grupo dos coliformes foi confirmada com produção de gás.

\subsection{PADRÃO MICROBIOLÓGICO}

Foi observado o regulamento técnico dos princípios gerais para estabelecimento de critérios microbiológicos para açúcares, adoçantes e similares no Anexo II da Agência de Vigilância Sanitária, de outubro de 1999.

Segundo a Portaria no 367, de 04 de setembro de 1997 do Ministério do Abastecimento, os padrões microbiológicos para o mel são: ausência de coliformes totais/g em cinco amostras analisadas de um lote e presença de no máximo $100 \mathrm{UFC} / \mathrm{g}$ de bolores e leveduras em duas amostras de cinco analisadas de um mesmo lote.

\subsection{SUJIDADE}

Foi depositada 1 gota de mel e 1 gota de solução de glicerina iodada numa lâmina para observar no microscópio.

\section{RESULTADOS E DISCUSSÃO}

\subsection{Contagem de Microrganismos}

Dos méis analisados foi detectada a presença de coliformes totais 
LIMA, R.S. et al. Contaminação microbiológica em mel de abelhas (Apis mellifera) não inspecionado comercializado no Mercado da Produção em Maceió. PUBVET, Londrina, V. 5, N. 6, Ed. 153, Art. 1028, 2011.

(Figura 1) em $60 \%$ das amostras e termotolerantes em $30 \%$ (Figura 2).

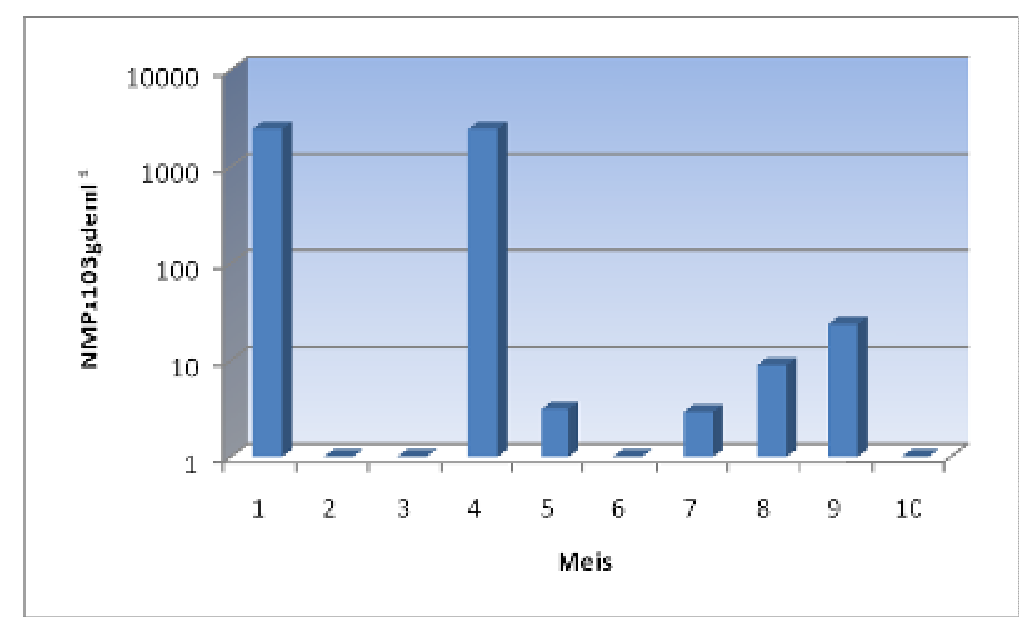

Figura 1. Número mais provável (NMP) de coliformes totais detectados em méis não inspecionados comercializados no mercado da produção em Maceió.

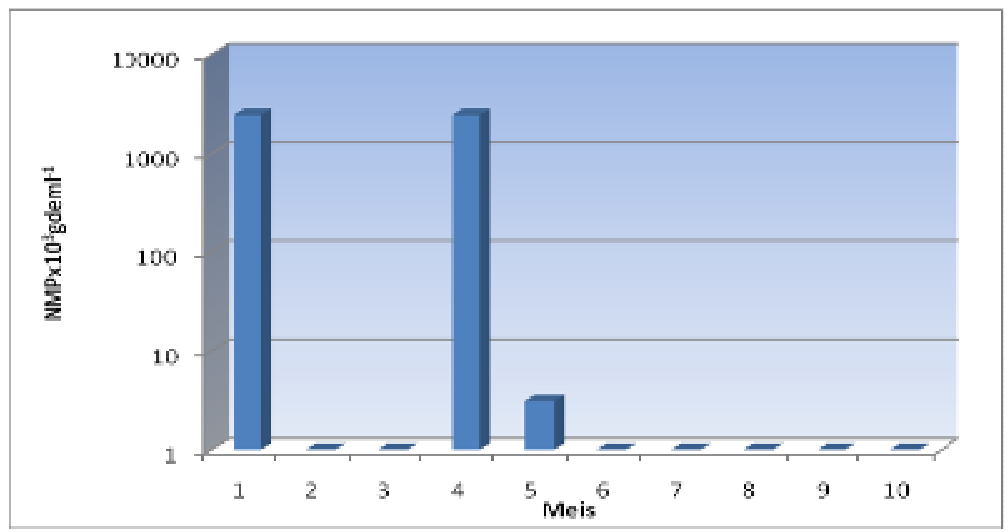

Figura 2. Número mais provável (NMP) de coliformes termotolerantes detectados em méis não inspecionados comercializados no mercado da produção em Maceió.

Os valores obtidos variaram de 3 a $2400 \times 10^{3}$ NMP por grama de mel, muito acima daqueles recomendados na legislação para microrganismos totais e termotolerantes, indicando condições inadequadas de higiene ao longo do processamento do mel e que o produto possui qualidade higiênico-sanitária 
LIMA, R.S. et al. Contaminação microbiológica em mel de abelhas (Apis mellifera) não inspecionado comercializado no Mercado da Produção em Maceió. PUBVET, Londrina, V. 5, N. 6, Ed. 153, Art. 1028, 2011.

insatisfatória.

O mel produzido por Apis mellifera, quando comparado com outros produtos de origem animal, apresenta um baixo número e menor variedade de microrganismos, porém não é um alimento estéril, estando susceptível a contaminações. Esta contaminação pode estar associada à veiculação de microrganismos pelas próprias abelhas melíferas, ao seu beneficiamento ou manipulação inadequada, além de más condições de armazenamento e acondicionamento (SILVA et al, 2004). A presença deste grupo de microrganismos indica contaminação secundária do produto, uma vez que estas bactérias necessitam de aw > 0,91 para seu crescimento (BOBBIO, 2001).

Os microrganismos pertencentes ao grupo dos coliformes refletem a qualidade microbiológica dos alimentos em relação à vida de prateleira ou à segurança, neste último caso, devido à presença de patógenos alimentares. Em geral, microrganismos indicadores, como o grupo dos coliformes, são utilizados para avaliar a sanificação dos alimentos. Contudo, os indicadores podem ser usados para avaliar aspectos gerais de qualidade, ou seja, os microrganismos indicadores são rotineiramente empregados para avaliar a qualidade do produto final e a higiene empregada no seu processamento.

As fontes secundárias (depois da colheita) que influenciam qualquer produto alimentício também são fontes de contaminação para o mel. Estas incluem os manipuladores, contaminação cruzada, equipamentos e instalações a manipulação incorreta, uso de materiais mal higienizados, locais inadequados e adulterações. O mel principalmente aquele não inspecionado pode sofrer adulterações mediante a mistura com cana de açúcar ou glicose.

Os resultados obtidos discordam de alguns trabalhos referentes à microbiologia do mel os quais demonstraram $<3,0$ UFC $\mathrm{g}^{-1}$. Alguns desses estudos são: Sereia (2005), que comparou as características microbiológicas de 17 méis orgânicos (11) e não orgânicos (6) produzidos na tríplice fronteira 
LIMA, R.S. et al. Contaminação microbiológica em mel de abelhas (Apis mellifera) não inspecionado comercializado no Mercado da Produção em Maceió. PUBVET, Londrina, V. 5, N. 6, Ed. 153, Art. 1028, 2011.

(entre os estados de São Paulo, Paraná e Mato Grosso do Sul); Sodré et al. (2007), os quais analisaram 58 amostras de mel do Ceará (20) e Piauí (38). Duarte et al., (2006) que avaliaram a qualidade microbiológica de méis produzidos na cidade de Pão-de-Açúcar no Estado de Alagoas.

Em amostras de mel de Camarões, produzido por $A$. mellifera, Tchoumboue et al. (2007) encontraram presença de contaminação por microrganismos em mais de $73,4 \%$ das amostras analisadas, atribuindo esta contaminação ao processamento pós-colheita ou adulteração do produto, uma vez que sua amostra de mel testemunha não apresentou estes níveis de contaminação.

Avaliando a qualidade microbiológica de amostras de mel de abelhas sem ferrão submetido a diferentes métodos de colheita (método do produtor e método asséptico), Oliveira et al. (2005) verificaram que, apesar de em nenhum dos dois métodos ter sido verificada a presença de microrganismos do grupo coliforme, a contagem de bolores e leveduras em $65 \%$ das amostras colhidas pelos produtores estava acima do máximo estabelecido pelas normas brasileiras, contra $25 \%$ das colhidas assepticamente.

Os resultados obtidos para microrganismos aeróbios mesofílicos encontram-se na Figura 3 , os valores obtidos variaram de 0 a $1,5 \times 10^{7}$. A contagem de microrganismos aeróbios mesófilos revelou-se um excelente parâmetro para avaliar quantitativamente a contaminação das amostras analisadas. Contagens tão altas quanto $10^{5} \mathrm{UFC} / \mathrm{g}$ foram detectadas em $90 \%$ das amostras sendo que apenas um apresentou resultado negativo para esta análise. Este resultado é um indicativo de adulteração do produto. 
LIMA, R.S. et al. Contaminação microbiológica em mel de abelhas (Apis mellifera) não inspecionado comercializado no Mercado da Produção em Maceió. PUBVET, Londrina, V. 5, N. 6, Ed. 153, Art. 1028, 2011.

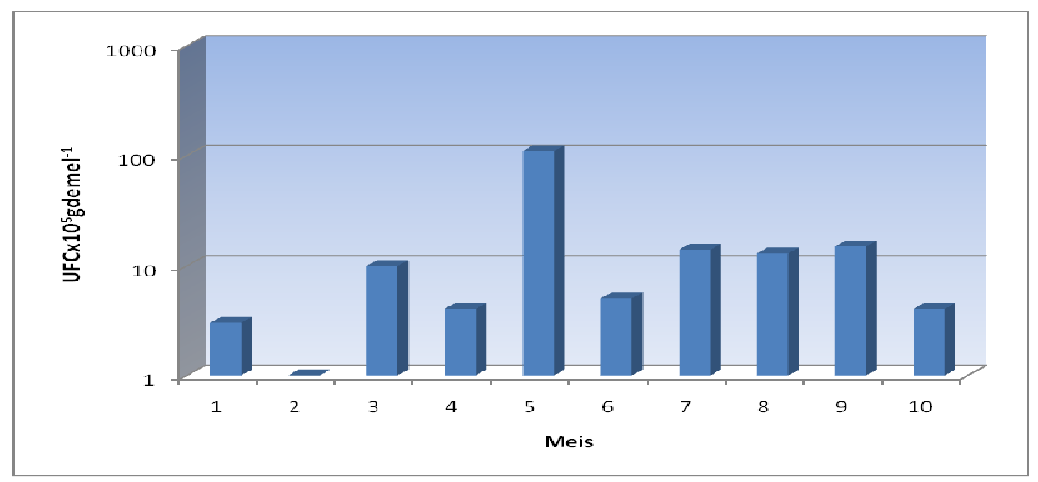

Figura 3. Número de unidades formadoras de colônias (UFC) detectadas em meis não inspecionados comercializados no mercado da produção em Maceió.

Os microrganismos possuem um nível limite de atividade de água abaixo do qual não conseguem se desenvolver, sendo as bactérias mais exigentes comparadas aos bolores e leveduras. A maioria das bactérias deterioradoras não se desenvolve em meio com aw < 0,91, mas sob condições aeróbias a atividade de água inibitória é de aw $=0,86$. Os substratos com aw $<0,6$ estão assegurados quanto à deterioração microbiana, mas a partir deste ponto começa a ocorrer a proliferação de fungos e leveduras, ao passo que fungos micotoxigênicos têm como limite de crescimento aw $=0,78$.

Garcia-Cruz et al (1999) em estudo para determinar a qualidade microbiológica de vinte amostras de mel comercializadas em varejo por pequenos agricultores na região de São José do Rio Preto - SP, verificaram que as contagens de bactérias aeróbias mesófilas variaram de $0,5 \times 10$ a $2,2 \times 10^{3}$.

Avaliando a qualidade microbiológica de amostras de mel produzido por cinco espécies de abelhas sem ferrão no Estado de São Paulo ( $T$. angustula, $S$. bipunctata, N. testaceicornis, F. varia e Tetragona clavipes), Almeida-Anacleto (2007) encontrou um total de 20 amostras (correspondendo a $64,5 \%$ do total analisado) com contagem de bolores e leveduras acima do permitido pela regulamentação brasileira, variando entre $1,50 \times 10^{2}$ e 1,58 $\times 10^{4}$ trigoníneos UFC. $\mathrm{g}^{-1}$. Nesse estudo, as espécies $S$. bipunctata e $T$. angustula foram, dentre 
LIMA, R.S. et al. Contaminação microbiológica em mel de abelhas (Apis mellifera) não inspecionado comercializado no Mercado da Produção em Maceió. PUBVET, Londrina, V. 5, N. 6, Ed. 153, Art. 1028, 2011.

as espécies com mais de cinco amostras, as que apresentaram um maior percentual de desclassificação, 83,4 e 60,0\%, respectivamente.

Duarte et al, (2006) avaliaram a qualidade microbiológica de méis produzidos na cidade de Pão-de-Açúcar no Estado de Alagoas e a presença de fungos filamentosos e leveduras foi detectada em contagens de até $10^{4} \mathrm{UFC} / \mathrm{g}$. Barros et al (2003) avaliaram a qualidade microbiológica de méis comercializados na região metropolitana de Recife utilizando a contagem de fungos filamentosos e leveduras como critério para avaliar quantitativamente a contaminação das amostras analisadas, encontrando contaminações de até $10^{2}$ UFC/g e Vargas(2006) encontrou contagem média de $1,3 \times 10^{3} \mathrm{UFC} / \mathrm{g}$ em méis produzidos na região dos Campos Gerais no Estado do Paraná.

No que se refere às contagens de bolores e leveduras nenhuma das amostras apresentaram valores acima do permitido dentro da legislação, que estabelece como limite máximo $100 \mathrm{UFCg}^{-1}$ de amostra.

As leveduras são microrganismos que podem crescer no mel por tolerar as condições ácidas e níveis altos de sacarose, enquanto que as leveduras osmofílicas crescem quando a pressão osmótica é alta, inclusive no mel maduro, fermentando-o facilmente. A fermentação do mel resulta no crescimento da levedura convertendo o açúcar em álcool, gás carbônico, ácidos orgânicos e outras combinações com sabores e odores indesejáveis (SNOWDON, 1999). As leveduras encontradas no mel de A. mellifera com predominância são: Saccharomyces, Schizosaccharomyces e Torula.

Para Crane (1975) condições que favorecem a fermentação do mel incluem elevada umidade (acima de 21\%), temperatura moderada, granulação, alto conteúdo de leveduras e presença de cinzas e nitrogênio. Os fungos estão associados com o conteúdo intestinal das abelhas, colméias e pasto apícola. Fungos incluindo Aspergillus, Chatomium, Penicillium e Peyronelia têm sido isolados de fezes de larvas de $A$. mellifera e do mel. 
LIMA, R.S. et al. Contaminação microbiológica em mel de abelhas (Apis mellifera) não inspecionado comercializado no Mercado da Produção em Maceió. PUBVET, Londrina, V. 5, N. 6, Ed. 153, Art. 1028, 2011.

\subsection{Sujidades}

A Figura 4 apresenta os tipos de ocorrências de sujidades e matérias estranhas isoladas e nas amostras analisadas. Não foram encontrados materiais macroscópicos, no entanto as análises microscópicas detectaram matérias estranhas em $100 \%$ das amostras.

Os padrões de identidade e qualidade do mel requerem, quanto aos aspectos macroscópicos e microscópicos, que o produto esteja isento de substâncias estranhas de qualquer natureza, tais como: insetos, larvas, grãos de areia e outros (SOUZA; CARNEIRO, 2008).

Souza \& Carneiro (2008) em pesquisa de sujidades em 52 amostras de mel produzido no estado do Piauí verificaram que $43,75 \%$ continham larvas, $12,5 \%$ ácaros e $62,5 \%$ fragmentos de insetos, pêlos de abelhas e pólen, e algumas apresentavam própolis e cera, portanto, 30,77\% delas estavam fora dos padrões exigidos pela legislação vigente.

\section{CONCLUSÃO}

> Das amostras analisadas, somente $20 \%$ apresentaram boas condições higiênico-sanitárias.

$>$ A contagem de bactérias mesófilas revelou-se insatisfatória em 9 amostras das 10 analisadas.

$>$ A presença de sujidades ocorreu em todas as amostras.

\section{AGRADECIMENTOS}

Agradecemos a Fundação de Apoio e Amparo a Pesquisa de Alagoas - FAPEAL, pela bolsa de Iniciação Científica para realização deste trabalho. 
LIMA, R.S. et al. Contaminação microbiológica em mel de abelhas (Apis mellifera) não inspecionado comercializado no Mercado da Produção em Maceió. PUBVET, Londrina, V. 5, N. 6, Ed. 153, Art. 1028, 2011.

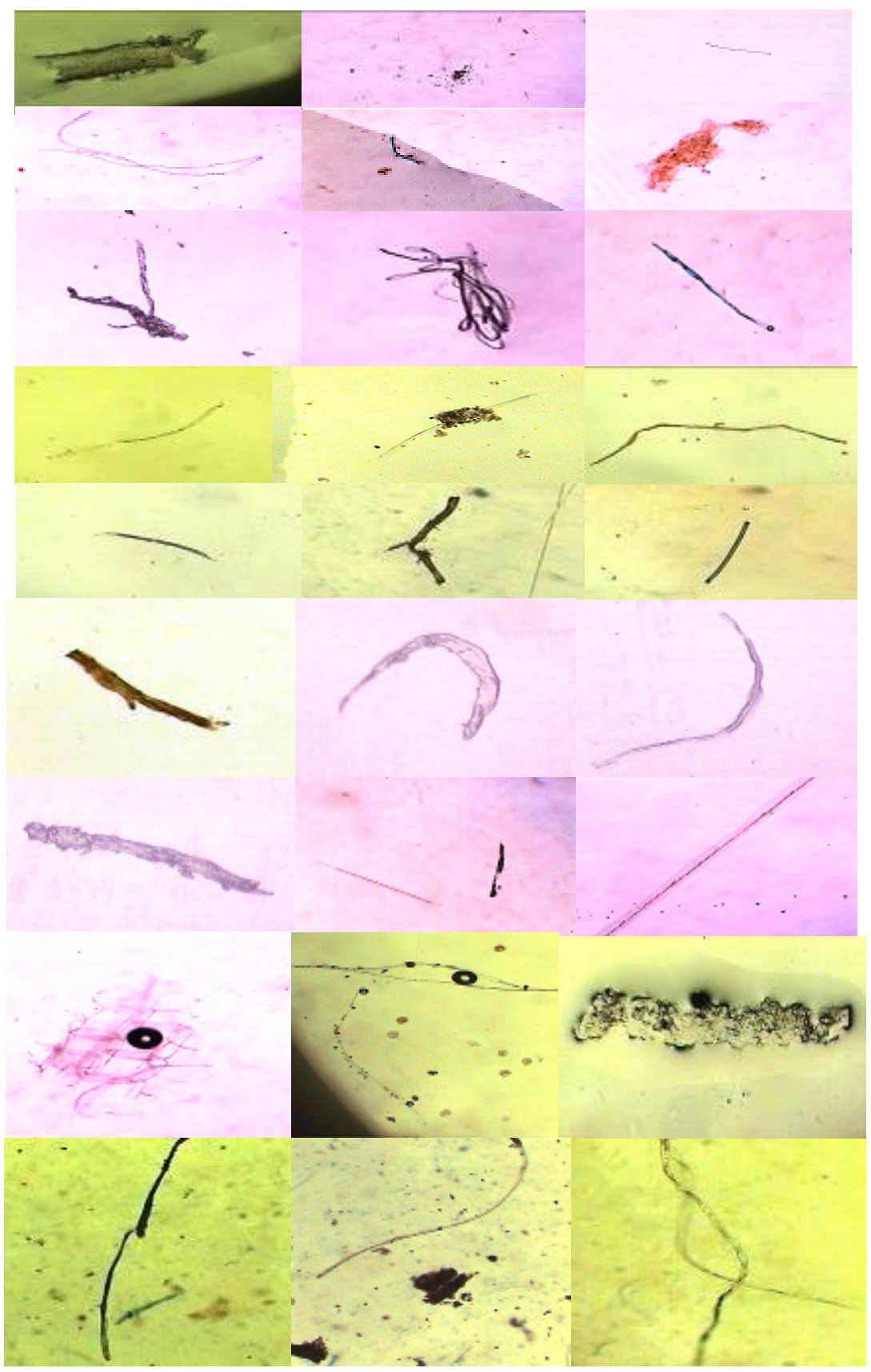

Figura 7. Sujidades encontradas nas amostras de mel.

\section{REFERÊNCIAS BIBLIOGRÁFICAS}

ABNT - ASSOCIAÇÃO BRASILEIRA DE NORMAS TÉCNICAS. Bactérias coliformes totais, coliformes fecais e Escherichia coli em alimentos: Determinação do número mais provável (NMP): MB-3463. Rio de Janeiro, 1991, 7p. 
LIMA, R.S. et al. Contaminação microbiológica em mel de abelhas (Apis mellifera) não inspecionado comercializado no Mercado da Produção em Maceió. PUBVET, Londrina, V. 5, N. 6, Ed. 153, Art. 1028, 2011.

ALMEIDA-ANACLETO, D. de. Recursos alimentares, desenvolvimento das colônias e características físico-químicas, microbiológicas e polínicas de mel e cargas de pólen de meliponíneos, do município de Piracicaba, Estado de São Paulo. Piracicaba, 2007. 133 p. Tese (Doutorado em Entomologia) - Escola Superior de Agricultura "Luiz de Queiroz", Universidade de São Paulo. Piracicaba-São Paulo.

BOBBIO, F. O.; BOBBIO, P. A. Química do processamento dos alimentos. 3 ed. São Paulo: Varela, 2001. 144 p.

CAMARGo, R.C.R.; PEReirA, F.M.; LOPES, M.T.R. Sistema de Produção de Mel. 1. ed. Teresina: Embrapa Meio-Norte, v. 1., 133 p., 2002.

CORREIA, M.; RONCADA, M. J. Padronização de métodos e quantificação de matérias estranhas e filamentos micelianos. I. Doces de frutas em pasta. Rev. Inst. Adolfo Lutz, v. 62 , n. 2, p. 85-90, 2002.

CRANE, E. Honey. London: Morrison and Gibb, 1975. 608 p.

CRANE, E. O Livro do mel. 2. ed. São Paulo. Livraria Nobel, 1987. p. 226.

SNOWDON, J. A.; CLIVER, D. O. Microorganisms in honey, Review article, International Journal of Food Microbiology, v. 31, p. 1-26, 1996.

DUARTE, A. W. F. et al. Avaliação da qualidade microbiológica de méis coletados em casas de mel no município de Pão-de-Açúcar - AL. In: CONGRESSO BRASILEIRO DE APICULTURA, 16, 2006, Aracaju.Anais... Aracaju: CBA, 2006. CD-ROM

ETTINGER, S. Macronutrientes: carboidratos, proteínas e lipídeos. In: Krause - Alimentos, nutrição e dietoterapia, São Paulo, cap.3, p 30-64, 2002.

GARCIA-CRUZ, C., HOFFMANN, F., SAKANAKA, L., \& VINTURIM, T. (2009). DETERMINAÇÃO DA QUALIDADE DO MEL. Alimentos E Nutrição Araraquara, 10(1). Disponível em http://serv bib.fcfar.unesp.br/seer/index.php/ alimentos/article/view/763/649. Acesso em 13/06/2010

GOMES, L. P. Contaminação bacteriana em amostras de méis de Apis mellifera L. comercializados no Estado do Rio de Janeiro. 2006. 46f. Dissertação (Mestrado em Microbiologia Veterinária) -Universidade Federal Rural do Rio deJaneiro. Seropédica-Rio de Janeiro,2006.

HAISIG, M.; KAMBUROY, G. Yeast from the larvae of healthy honey bee colonies, 1966. Apud: SNOWDON, J. A.; CLIVER, D. O. Microorganisms in honey, Review article, International Journal of Food Microbiology, v. 31, p. 1-26, 1996.

MADIGAN, M.T.; MARTINKO, J.M.; PARKER, J. MIcrobiologia de Brock. São Paulo: Editora Pearson-Prentice Hall, 2004. 608p.

MIDURA, T.F.; SNOWDEN, S.; WOOD, R.M.; ARMON, S.S. Isolation of Clostridium botulinum from honey, 1979. Apud: SNOWDON, J. A.; CLIVER, D. O. Microorganisms in honey, Review article, International Journal of Food Microbiology, v. 31, p. 1-26, 1996.

Ministério da Agricultura, Pecuária e do Abastecimento (MAPA), Qualidade dos Produtos Regulamento técnico de identidade e qualidade do mel, Instrução Normativa $n^{\circ} 11$, de 20 de outubro de 2000. Diário oficial da união de 20 de outubro de 2000, seção 1, p. 16-17.

MONETTO, A.M.; FRANCAVILLA, A.; RONDINI, A.; et al. A study of botulinum spores in honey. Anaerobe, v.5, p. 185-186, 1999.

PARREIRAS, L. E. Negócios solidários em cadeias produtivas: protagonismo coletivo e 
LIMA, R.S. et al. Contaminação microbiológica em mel de abelhas (Apis mellifera) não inspecionado comercializado no Mercado da Produção em Maceió. PUBVET, Londrina, V. 5, N. 6, Ed. 153, Art. 1028, 2011.

desenvolvimento sustentável. Rio de Janeiro: IPEA, 2007.

OLIVEIRA, E. G. et al. Qualidade microbiológica do mel de tiúba (Melipona compressipes fasciculata) produzido no Estado do Maranhão. Higiene alimentar, v. 19, n. 133, p. 92-99, 2005.

RUIZ, Rogério Lacaz. Microbiologia zootécnica. In: Microbiologia da ração. São Paulo: Roca, 1992. Cap. 13. p. $289-314$.

SOUSA, Ricardo Silva de; CARNEIRO, Júlia Geracila de Mello e. Pesquisa de sujidades e matérias estranhas em mel de abelhas (Apis mellifera L.). Ciênc. Tecnol. Aliment., Campinas, v. 28, n. 1, Mar. 2008 . Available from $<$ http://www.scielo.br/scielo.php?script=sci_arttext\&pid=S010120612008000100006\&lng=en\&nrm=iso $>$. access on 13 June 2010. doi: 10.1590/S010120612008000100006.

SODRÉ, G. da S. et al. Conteúdo microbiológico de méis de Apis mellifera (Hymenoptera: Apidae) dos Estados do Ceará e Piauí. Boletim de Indústria Animal, v. 64, n. 1, p. 39-42, 2007.

TCHOUMBOUE, J. et al. Physico-chemical and microbiological characteristics of honey from the sudano-guinean zone of West Cameroon. African Journal of Biotechnology, v. 6, n. 7, p. 908-913, 2007.

VANDERZANT, C. \& SPLITTSTOESSER, D.F. Compendium of methods for the microbiological examination of foods. 3 ed. Washington: American Public Health Association, 1992. $1219 p$.

VARGAS, T. Avaliação da qualidade do mel produzido na região dos Campos Gerais do Paraná. 2006. 116f. Dissertação (Mestrado em Ciência e Tecnologia de Alimentos) - Departamento de Tecnologia de Alimentos, Universidade Estadual de Ponta Grossa. Ponta Grossa-Paraná. 